\title{
LA-UR $91-3235$
}

TITLE: MECHANISMS UNDERLYING THE REDISTRIBUTION OF PARTICLES AMONG THE LUNG'S ALVEOLAR MACROPHAGES DURING ALVEOLAR PHASE CLEARANCE

AUTHOR(S): Bruce E. Lehnert, Jeanelle B. Ortiz, John A. Steinkamp, Gary L. Tietjen, Robert J. Sebring and Gunter Oberdorster

SUBMITTED TO: $\quad 7$ th International Symposium on Inhaled Particles

\author{
DISCLAIMER
}

\begin{abstract}
This report was prepared as an account of work sponsored by an agency of the United States Government. Neither the United States Government nor any agency thereof, nor any of their employees, makes any warranty, express or implied, or assumes any legal liability or responsibility for the accuracy, completeness, or usefulness of any information, apparatus, product, or process disclosed, or represe., ts that its use would not infringe privately owned rights. Reference herein to any specific commercial product, process, or seivice by trade name, trademark, manufacturer, or otherwise does not necessarily constitute or imply its endorsement, recommendation, or favoring by the United States Government or any agency thereof. The views and opinions of authors expressed herein do not necessarily state or reflect those of the United States Government or any agency thereof.
\end{abstract}




\title{
MECHANISMS UNDERLYING THE REDISTRIBUTION OF PARTICLES AMONG THE LUNG'S ALVEOLAR MACROPHAGES DURING ALVEOLAR PHASE CleARANCE
}

\author{
B.E. Lehnert' ${ }^{1}$, J.B. Ortiz'1 , J.A. Steinkamp'1, G.L. Tietjen', R.J. Sebring ${ }^{1}$, and G. Oberdorster², \\ ${ }^{1}$ Los Alamos National Laboratory, Los Alamos, NM, U.S.A., \\ and 2 University of Rochester, Rochester, NY, U.S.A.
}

\begin{abstract}
Evidence obtained following the intratracheal instillation of polystyrene microspheres has suggested that relatively insoluble particles are gradually redistributed among the lung's population of alveolar macrophages (AM) during alveolar phase clearance. In order to obtain intormation about the particle redistribution phenomenon following the deposition of inhaled particles, as well as to obtain information about some of the mechanisms that may be operable in the redistribution of particles, lavaged lung free cell analyses and transmission electron microscopic (TEM) analyses of lung tissue and were performed using lungs from rats after they were subchronically exposed to aerosolized titanium dioxide $\left(\mathrm{TiO}_{2}\right)$. Results from assessments of particulate $\mathrm{TiO}_{2}-\mathrm{AM}$ relationships during the clearance of the particles were consistent with a gradual redistribution of the $\mathrm{TiO}_{2}$ among the lung's AM. TEM analyses indicated that the in situ autolysis of particle-containing $A M$ is one important mechanism involved in the redistribution of particles. Evidence was also obtained that indicated that the engulfment of one particlecontaining phagocyte by another phagocyte also occurs. Based on the observation of mitotic figures of particle-containing AM among lavaged lung free cells after particle deposition in the lung, as well as other lines of evidence that AM can replicate, another prominent mechanism of the particle redistribution phenomenon may be the in situ proliferation of particle-laden AM. In another component of the study, accordingly, we used the macrophage cell line J774A.1 as a surrogate for $A M$ to investigate how different particulate loads in macrophages may affect their abilities to proliferate, and to quantitatively examine how particles are allocated from particleladen parent macrophages to their progeny. These in vitro investigations indicated that the normal rate of proliferation of macrophages is essentially unaffected by the containment of relatively high particulate burdens. Additionally, evidence was obtained that is consistent with the possibility that the allocation of particles to progeny macrophages is an uneven process. Overall, the results of our investigations suggest that the in situ autolysis of particle-

containing AM and the rephagocytosis of freed particles by other phagocytes, the phagocytosis of effete and disintegrating particle-containing phagocytes by other $A M$, and the in situ division of particle-containing $A M$ are likely mechanisms that underlie the post-depositional redistribution of particles among the lung's AM during alveolar phase clearance.
\end{abstract}

\section{INTRODUCTION}

Our previous investigations of the particle redistribution phenomenon have involved analyses of particle-lavaged AM relationships during the alveolar clearance of intratracheally instilled polystyrene microspheres (LEHNERT et al, 1989; LEHNERT, 1990; LEHNERT et al, 1991; LEHNERT, 1991). In the current study, we set out to investigate the particle redistribution phenomenon following a subchronic exposure of rats to aerosolized titanium 
dioxide $\left(\mathrm{TiO}_{2}\right)$ by also examining the distributions of the $\mathrm{TiO}_{2}$ among $\mathrm{AM}$ lavaged during its atveolar phase clearance, and by performing transmission electron microscopic analyses of the lungs of the $\mathrm{TiO}_{2}$-exposed animals in order to obtain evidence of the processes that may underlie the redistribution of particles among the lung's AM in situ.

In a second component of our study, we performed in vitro analyses of how the engulfment of particles by macrophages may affect their abilities to replicate and how particles may be allocated to the progeny of proliferating macrophages using a macrophage cell line as a surrogate for AM inasmuch as the in situ proliferation of AM (e.g., TARLING and COGGLE, 1982; SAWYER, 1986; EVANS, 1986; TARLING et al, 1987; SHELLITO et al, 1987) may be involved in the dispersion of particles among the lung's AM over time.

\section{METHODS}

\section{Particle-Alveolar Macrophage Relationships During the Clearance of}

Inhaled Particulate Titanium Dioxide: Male, Fischer 344 rats (SPF, 240-260 g) were exposed to aerosolized titanium dioxide $\left(\mathrm{TiO}_{2}\right.$, anatase, Fischer Scientific, Springfield, $\left.\mathrm{NJ}\right)$ in a $300 \mathrm{~L}$ whole body chamber using horizontal laminar flow in conjunction with a Wright Dust Feed generator (FERIN et al, 1991). The animals were exposed to an average concentration of $\sim 23 \mathrm{mg} / \mathrm{m}^{3}$ of the $\mathrm{TiO}_{2}\left(\mathrm{MMAD}: 0.71 \mu \mathrm{m}, \sigma_{\mathrm{g}}: 1.9\right)$ for $6 \mathrm{hr}$ per day, 5 days per week, for 12 weeks. A control group of rats was exposed to filtered air only. One day after the last day of exposure, and as of 6 months and 1 year after cessation of the exposures, the lungs of sacrificed animals were either excised and lavaged or fixed for light and electron microscopic analyses using conventional tissue processing techniques. The lavage protocol consisted of 10 lung washings, with $5 \mathrm{ml}$ of room temperature, normal saline being used for each lung wash cycle. Lavage fluids recovered from each animal were pooled and subsequently analyzed for cell numbers and types. The amounts of $\mathrm{TiO}_{2}$ present in centrifuged lavaged cell samples and in lavaged lung tissue were quantitated by direct current plasma atomic emission spectroscopy (FERIN et al, 1991).

Estimates of the relative cellular burdens of $\mathrm{TiO}_{2}$ in individual $\mathrm{AM}$ were made using cytocentrifuged slide preparations of lavaged cells and an image analysis system (Dapple Systems, Sunnyvale, CA). Randomly selected fields of cells were imaged on a Zeiss light microscope equipped with a $40 \mathrm{X}$ plan objective. A B/W video image of the cells was transmitted from the microscope to the image analysis system via a CCD camera attached to the microscope; final magnification was $1620 \mathrm{X}$. The video image was digitized to a computer image consisting of 64 gray levels at a resolution of $256 \times 256$ pixels. A binary image representing the $\mathrm{TiO}_{2}$ was generated using gray level thresholding (RUSS and RUSS, 1984). Each binary image was edited so the reference area, which consisted of the total digitized field that was precalibrated in $\mu \mathrm{m}^{2}$, 
included only $\mathrm{TiO}_{2}$ associated with one cell. The estimate of the $\mathrm{TiO}_{2}$ in an $\mathrm{AM}$ was made by determining the percentage of the total reference area occupied by the $\mathrm{TiO}_{2}$. This procedure was repeated until data were obtained for 100 AM per lavage sample.

Particles and the Proliferation of Macrophages In Vitro: We used a mouse macrophage cell line (J774A.1) as a surrogate for AM in order: 1) to determine how particles engulfed by macrophages may affect their subsequent abilities to proliferate, and 2) to obtain information as to how particles may be distributed from -article-containing, replicating macrophages to progeny cells. The J774A.1 macrophages were cultured in $35 \mathrm{~mm}$ dia. culture plates using $10 \%$ fetal bovine serum in minimum essential medium (FBS-MEM). Monolayers of the macrophages were incubated with FBS-MEM that contained sterile, green fluorescent polystyrene microspheres $\left(\sim 2.0 \mu \mathrm{m}\right.$ dia.) at a concentration of $\sim 1.6 \times 10^{8}$ particles $/ \mathrm{mL}$. One hour thereafter, the cells were jetted off the plates using collagenase, and the cells were centrifuged and resuspended in FBS-MEM at a concentration of $\sim 1 \times 10^{6}$ cells $/ \mathrm{mL}$. Control J774A.1 cells were incubated with FBS-MEM without particles and likewise processed. After incubation with particles, the macrophages were analysed with a flow cytometer. Groups of viable cells were arbitrarily sorted according to their relative particle loads, i.e., green fluorescence intensity, for subsequent culture. These groups consisted of macrophages that contained a low burden of particles, a low-medium burden of particles, a high-medium burden of particles, and a high burden of particles, Figure 1. Other control groups for the proliferation studies consisted of macrophages that were not treated with particles but sorted by the flow cytometer, and macrophages that were incubated with particles but not passed through the flow cytometer; these latter cells, referred to hereafter as the "parent population", were centrifuged through a cushion of serum in order to remove free particles prior to subsequent in vitro culture. Another control group consisted of macrophages that received no experimental treatment prior to culture.

After sorting, the cells were centrifuged and resuspended in FBS-MEM to a concentration of $7.5 \times 10^{3}$ cells $/ \mathrm{mL}$. Two $\mathrm{mL}$ of these suspensions were added to individual culture plates for the cell proliferation assays. Triplicate plates were set up for each macrophage group for analysis at each post-sorting time point. Cell proliferation was measured by hemocytometrically counting cells removed from the plates daily over a 6 day period. Cell cytocentrifuged slide preparations were made from the plates at each time point. These samples were used to visually count (fluorescence-light microscopy) the numbers of microspheres in the cells harvested from the plates ( 300 cells analyzed/sample).

In attempts to "model" macrophage proliferation and particle allocations to progeny cells, we used a pure birth model and an arbitrary number of "starting" macrophages $(1,000)$. 
We assigned each macrophage a particle burden based on the frequency distribution of particles in the parent cell population as determined at time zero. Given a lag time of $\sim 24 \mathrm{hr}$ and a doubling time of $\sim 15 \mathrm{hr}$ (to be discussed), we took expected division times at $39(24+15)$, $54,69,99$, and $114 \mathrm{hr}$ and considered the possibility that allocations to daughter cells may be uneven. This was modeled by considering all the possible ways a cell can allocate its particulate burden to its next generation progeny and by assigning a probability to each of these possibilities. We next calculated the number of cells containing each particle burden at each of the $15 \mathrm{hr}$ division times. With this model, the total number of cells containing, say, 3 particles at a given time is the number that results from divisions of cells with 3 or more particles in the preceding generation.

\section{RESULTS}

\section{Particle-Alveolar Macrophage Relationships During the Clearance of} Inhaled $\mathrm{TiO}_{2}$ : For background information, the post-exposure lung retention data for the $\mathrm{TiO}_{2}$ and lavaged lung free cell data (referenced to lung free cell data obtained from animals exposed to filtered air only) are shown in Figure $2 A$ and Table 1, respectively. As indicated in Figure $2 \mathrm{~A}$, the long term retention half-time $\left(t_{1 / 2}\right)$ of the $\mathrm{TiO}_{2}$ was $\sim 174$ days, and, as suggested by the results of our analyses of $\mathrm{TiO}_{2}$ in the lavaged samples, Figure 2B, most of the retained $\mathrm{TiO}_{2}$ was associated with the lung's free cell population. Though the total free cell numbers and $A M$ numbers from $\mathrm{TiO}_{2}$ exposed lungs appeared to be somewhat elevated above control values as of one day and six months after cessation of exposure, these latter cellular parameters numerically remained relatively constant over the course of the study. We note here that such findings suggest that the rate of removal of AM from the lung during AM-mediated particle clearance (LEHNERT and MORROW, 1985) or other processes was balanced by a comparable rate of $A M$ replenishment.

The distributions of $\mathrm{TiO}_{2}$ in $\mathrm{AM}$ lavaged one day after the 12 week exposure to aerosolized $\mathrm{TiO}_{2}$ and in $\mathrm{AM}$ harvest from groups of rats sacrificed six months and one year after the exposure are summarized in Figure 3. It should be emphasized that the values expressed as $\mu \mathrm{m}^{2}$ in Figure 3 are relative indicies of the cellular burdens of $\mathrm{TiO}_{2}$ in the $\mathrm{AM}$. The approach used for obtaining the particle distribution data was selected primarily because of its sensitivity to detect cells with lesser burdens of particles; we made no attempt to estimate the absolute amounts of $\mathrm{TiO}_{2}$ in the AM because of the problem of the piling of particles in cytocentrifuged cells. Regardless, nearly all AM were found to contain $\mathrm{TiO}_{2}$ on the day after cessation of the exposure, i.e., less than $\sim 2 \%$ contained no detectable particles, with the majority of cells containing particles in the higher particle burden categories. At six months and one yea: after exposure, less than $\sim 11 \%$ of the lavaged $A M$ remained particle free. The 
majority of the AM harvested at these times were in the lower particle burden categories.

The transmission electron micrographs shown herein were obtained from the lungs of rats sacrificed six months after exposure to the $\mathrm{TiO}_{2}$. Observed processes that likely underlie the particle redistribution phenomenon include the in situ autolysis of $A M$ and the uptake of released particles by other $A M$ and newly recruited polymorphonuclear leukocytes (PMN), and the phagocytosis of particle-containing effete and degenerating phagocytes by other phagocytes, Figures 4-6.

Particles and the Proliferation of Macrophages: Virtually all of the J774A.1 cells sorted from the various particle burden categories illustrated in Figure 3 contained microspheres, Table 2. As expected, the average number of microspheres initially contained in each sorted fraction of macrophages, Table 2, increased with increasing green fluorescence intensities, which in turn were attributable to the magnitudes of the particulate loads in the cells. After an $\sim 24 \mathrm{hr}$ lag period culture, untreated J774A.1 cells underwent exponential growth for at least 5 days. The doubling time for the cells over this period of time was $\sim 15 \mathrm{hr}$. As illustrated in Figure 7, the proliferation kinetics of the various particle-containing populations of macrophages were similar if not identical to the proliferation characteristics of sorted macrophages that were not treated with particles. Thus, no evidence was found to indicate that the rate of proliferation of macrophages was importantly altered by their containment of the particles.

For the sake of brevity, only our analyses of the particle distributions in the "parent population" of macrophages and their progeny after in vitro culture are summarized in this report. The percentages of these cells that contained no particles progressively increased as the macrophages proliferated, while the percentages of the macrophages in the higher particle burden categories gradually decreased over time, Figure 8 . The results from our attempt to model particle allocations to progeny cells during the proliferation of the macrophages are compared to the actual observed particle distribution data in Figure 8 . The results indicate that the pure birth model with an uneven allocation of particles to progeny cells is approximately correct; at least it preserves the shape and direction of the observed data histograms.

\section{DISCUSSION}

In previous studies involving analyses of particle-AM relationships following the intrairacheal instillation of polystyrene microspheres, we obtained evidence that suggested that particles engulfed by AM shortly after being acutely deposited in the lung gradually become dispersed or redistributed among the lung's population of AM (LEHNERT et al, 1989; LEHNERT, 1990; LEHNERT et al, 1991; LEHNERT, 1991). In the present study, we have obtained 
evidence from our present analyses of particle-AM relationships that the particle redistribution phenomenon occurs following the deposition of particles that are subchronically inhaled as aerosol, and that if occurs with a another type of particulate material, i.e., $\mathrm{TiO}_{2}$. Specifically, we have found that only $\sim 10 \%$ of the lavaged $A M$ remained particle-free up to a year after cessation of exposure to aerosolized $\mathrm{TiO}_{2}$. Given the relative stability in the AM population size and the lung retention kinetics of the $\mathrm{TiO}_{2}$ observed in our study, and assuming: 1) most of the particles that were removed from the lung during the one year post-depositional period underwent AM-mediated particle clearance (LEHNERT and MORROW, 1985; LEHNERT et al, 1989), 2) deposited particles were sequestered in $A M$ that originally phagocytized them with complete fidelity until the AM were removed from the lower respiratory tract via the tracheobronchiole route, and 3) AM that were removed from the lung were replaced by newly arrived, particle-free mononuclear phagocytes, substantially higher percentages of particlefree AM would be predicted (LEHNERT et al, 1991) at the six month and one year postdepositional time points, e.g., $\sim 53 \%$ and $\sim 72 \%$, respectively. While our experimental results could also be interpreted to reflect: 1) the gradual entry of macrophages containing low burdens of particles into the alveolar space compartment, such as interstitial macrophages, and/or 2) that more heavily burdened macrophages tend to be removed from the lung via mucociliary transport, several lines of evidence argue against these explanations exclusively. With regard to the first interpretation, comparisons of the amounts of $\mathrm{TiO}_{2}$ in the lavaged cells relative to the total retained lung burdens of $\mathrm{TiO}_{2}$ revealed that most of the retained particles were in the alveolar space compartment. Along the same line, in other analyses not detailed herein, we found that even after a year following exposure to the $\mathrm{TiO}_{2}$, only $\sim 300 \mu \mathrm{g}$ of the lung burden deposited during the 12 week exposure period n:as translocated to the regional hilar lymph nodes. Thus, it would appear that relatively little $\mathrm{TiO}_{2}$ ultimately gained access to the lung's interstitium where it could be phagocytized by interstitial macrophages. Moreover, our ultrastructural analyses of the $\mathrm{TiO}_{2}$-exposed lungs have so far indicated that relatively little of the retained $\mathrm{TiO}_{2}$ was in the lung's population of interstitial macrophages, at least those in the alveolar region. With regard to the second alternative interpretation, existing evidence is inconsistent with the notion that $A M$ with higher burdens of particles are more readily removed from the alveoli than are their lesser burdened counterparts (LEHNERT et al, 1990b). Contrarily, the rate of alveolar removal of AM with high particulate loads is diminished (MORROW, 1988; OBERDORSTER et al, 1988; LEHNERT, 1990).

The mechanisms responsible for the particle redistribution phenomerion are potentially numerous. In agreement with earlier findings reported by Heppleston (1961) and Heppleston and Young (1974), our electron microscopic analyses of the $\mathrm{TiO}_{2}$ exposed lungs have indicated that one important mechanism involved in the overall process is the in situ disintegration of 
particle-containing macrophages and the rephagocytosis of released particles by other $A M$ and PMN. Additionally, we have found evidence that another component of the redistribution of particles is the phagocytosis of effete particle-containing cells by other AM. While we previously presented evidence that AM can ingest particle-containing PMN during an acute free cell response to particle deposition in the lung (LEHNERT et al, 1985), our current investigation extends this observation by revealing that the phagocytosis of one particlecontaining phagocyte by another alveolar phagocyte can be an ongoing process during alveolar phase clearance.

Another mechanism that may be involved in the particle redistribution phenomenon is the intra-alveolar replication of particle containing AM. It is now widely recognized that the cell division of AM plays a role in maintaining the size of the lung's AM population (e.g., TARLING and COGGLE, 1982; EVANS, 1986; SAWYER, 1986; TARLING et al, 1987; SHELLITO et al, 1987). While we did not directly examine the role AM proliferation may play in gradually dispersing particles among the lung's AM over time in the present study, we did attempt to investigate such a process using a macrophage cell line as a surrogate for AM. If AM qualitatively behave in situ as do the J774A.1 macrophages in vitro, our findings suggest that the replication of $A M$ would not be importantly disturbed by their containment of relatively high burdens of particles. Additionally, our initial attempts to model macrophage proliferation concurrently with how particles are allocated to progeny cells suggests that the allocation of particles from replicating macrophages to daughter cells may be done unevenly. Factors that may have contributed to the disparities between the observed and "modeled" distributions of particles in the macrophages, e.g., cell death, particle exocytosis and rephagocytosis, and, perhaps, the fusion of particle-containing phagosomes, are currently undergoing further study. Regardless, the birthing mociel coupled to an uneven allocation of particles to progeny cells more closely tracts the actual experimental data than does the birthing model with the imposition that the particles are evenly allocated to daughter cells (LEHNERT et al, 1990a). Vue presently speculate that such information will take on added importance as we further develop a model (LEHNERT ef al, 1991) of particle-A'd relationships during alveolar clearance.

Finally, some brief mention should be made about the possible significance the particle redistribution phenomenon may have in the context of particle-induced lung diseases. If the overall process involves the release of free particles from phagocytes that have previously engulfed them, as our findings indicate, such free particles would again have the opportunity to interact with cells lining the alveolar epithelial surface (at times well after the particles were initially deposited) before being rephagocytized by other AM or newly recruited PMN. The magnitude of this effect would be expected to increase with increasing particle cytotoxicity. Additionally, free particles, however temporailly presenty, would again be afforded the 
opportunity to gain access to the lung's interstitium via Type I cell transepithelial transport. The rephagocytosis of freed particles by other lung phagocytes at times well after their initial deposition in the lung would also be expected to have some potentially detrimental consequences, including the intra-alveolar elaboration of mediators of inflammation, e.g., reactive oxygen species, proteases, some cytokines, prostaglandins and leukotrienes, by the phagocytizing cells. The role the particle redistribution phenomenon may have on the lung retention of particles remains a problematic area in need of further study, as discussed elsewhere (LEHNERT, 1990).

\section{Acknowledgements}

This work was supported by NIH Grants ES04872 and ES01247, and by a U.S. Department of Energy project entitled "Mechanisms of Pulmonary Damage". 


\section{REFERENCES}

Evans, M.J., Shami, S.G., Martinez, L.A.: Enhanced proliferation of pulmonary alveolar macrophages after carbon instillation in mice depleted of blood monocytes by strontium-89. Lab. Invest. 54:154-159, 1986.

Ferin, J., Oberdorster, G., Soderholm, S.C., Gelein, R.: Pulmonary tissue access of ultrafine particles. J. Aerosol Med. 4(1):57-68, 1991.

Heppleston, A.G.: Observations on the disposal of inhaled dust by means of the double exposure rechnique. In: Inhaled Particles and Vapours. C.N. Davies, Ed., Pergamon Press, New York, pp. 320-325, 1961.

Heppleston, A.G., Young, A.E.: Uptake of inert particulate matter from alveolar cells: An ultrastructural study. J. Pathol. 111:159-164, 1974.

Lehnert, B.E.: Alveolar macrophages in a particle "overload" condition. J. Aerosol Med. 3(S1):9-30, 1990.

Lehnert, B.E.: The particie redistribution phenomenon as a factor complicating microdosimetry in the lung. Radiat. Protect. Dosimetry, in press, 1991.

Lehnert, B.E., Morrow, P.E.: Association of 59 iron oxide with alveolar macrophages during alveolar clearance. ExD. Lung Res. 9:1-16, 1985.

Lehnert, B.E., Ortiz, J.B., Valdez, Y.E., Steinkamp, J.A.: Influence of particulate load on macrophage proliferation. The Toxicologist 10:A399, 1990a.

Lehnert, B.E., Toevs, K.E., Sebring, R.J., Valdez, Y.E.: Failure of a simple model of alveolar macrophage-mediated particle clearance to depict particle-alveolar macrophage relationships during early alveolar phase clearance. J. Aerosol Med. 4(1):41-56, 1991.

Lehnert, B.E., Valdez, Y.E., Bomalaski, S.H.: Lung and pleural "free-cell responses" to the intrapulmonary deposition of particles in the rat. J. Toxicol. Environ. Health 16:823-839, 1985. 
Lehnert, B.E., Valdez, Y.E., Sebring, R.J., Lehnert, N.M., Saunders, G.C., Steinkamp, J.A.: Airway intra-luminal macrophages: Evidence of origin and comparisons to alveolar macrophages. Am. J. Respir. Cell and Molecular Biol. 3:377-391, 1990b.

Lehnert, B.E., Valdez, Y.E., Tietjen, G.L.: Alveolar macrophage-particle relationships during lung clearance. Am. J. Respir. Cell Mol. Biol. 1:145-154, 1989.

Morrow, P.E.: Possible mechanisms to explain dust overloading of the lungs. Fund. Appl. Toxicol. 10:197-207, 1988.

Oberdorster, G., Ferin, J., Morse, P., Corson, N.M., Morrow, P.E.: Volumetric alveolar macrophage (AM) burden as a mechanism of impaired $A M$ mediated particle clearance during chronic dust overloading of the lung. J. Aerosol Med. 1:A207, 1988.

Russ, J.C., Russ, J.C.: Image processing in a general purpose microcomputer. J. Microscopy 135:89-102, 1984 .

Sawyer, R.T.: The significance of local resident pulmonary alveolar macrophage proliferation to population renewal. J. Leuk. Biol. 39:77-87, 1986.

Shellito, J., Esparza, C., Armstrong, C.: Maintenance of the normal rat alveolar macrophage cell population: The roles of monocyte influx and alveolar macrophage proliferation in situ. Am. Rev. P.espir. Dis. 135:78-82, 1987.

Tarling, J.D., Coggle, J.E.: The absence of effect on pulmonary alveolar macrophage numbers during prolonged period of monocytopenia. J. Reticuloendothel. Soc. 31:221-224, 1982.

Tariing, J.D., Lin, H.-S., Hsu, S.: Self renewal of pulmonary alveolar macrophages: Evidence from radiation chimera studies. J. Leuk. Biol. 42:443-446, 1987. 


\section{FIGURE LEGENDS}

Figure 1: Electronic volume, axial light loss, $90^{\circ}$ light scatter, and green fluorescence histograms obtained with the J774A.1 macrophages after incubation with the fluorescent microspheres. Red fluorescence signals due to propidium iodide (PI)-labeling of dead cells are not shown. Sorts of the cells were performed by sorting all PI-negative cells that had electronic volumes exceeding channel 25 for this parameter in conjunction with the indicated green fluorescence window ranges for the various particle burden categories. Only electronic volume was used to sort cells that were not incubated with the microspheres; in this case, all PI-negative events with electronic volume signals above channel 25 were sorted.

Figures 2A and 2B: $2 \mathrm{~A}$ ) Lung accumulation of $\mathrm{TiO}_{2}$ during the 12 week exposure period and the lung retention of the $\mathrm{TiO}_{2}$ over a 1 year period after cessation of exposure. $2 \mathrm{~B}$ ) The amount of $\mathrm{TiO}_{2}$ that was associated with centrifuged, lavaged cells during the 12 week exposure period and during the alveolar clearance of $\mathrm{TiO}_{2}$ after cessation of the aerosol exposures.

Figure 3: Relative burdens of $\mathrm{TiO}_{2}$ in $\mathrm{AM}$ harvested one day, 6 months, and 1 year after cessation of the $\mathrm{TiO}_{2}$ exposures. These data were obtained from cells lavaged from 3.4 rats per time point. Values for the standard errors of the means (not shown) were always less than $2 \%$.

Figure 4: Transmission electron micrograph showing a $\mathrm{TiO}_{2}$-containing $\mathrm{AM}$ (") which appears to be in an early stage of phagocytizing free particles (larger solid arrow), a disintegrating AM $(A M D)$, free particles released from the disintegrating $A M$ (longer, thin arrows), an $A M$ (larger open arrow) that is apparently in the process of engulfing the disintegrating $A M$, and a type I epithelial cell that has internalized $\mathrm{TiO}_{2}$ ( $\mathrm{TI}$, small arrow).

Figure 5: A particle-containing AM (AM) that has engulfed another cell (EC) that evidently had previously phagocytized $\mathrm{TiO}_{2}$.

Figure 6: A group of polymorphonuclear leukocytes (") that are in the process of phagocytizing free particles released from another disintegrating cell (DC).

Figure 7: In vitro proliferation of the various J774A.1 macrophage populations. 
Figure 8: The observed frequency distributions of particles in the J774A.1 cells and the frequency distributions of particles in the cells when calculated from the starting distribution of particles in the parent population using a simple birthing model and allowing the particles to distribute unevenly from relicating cells to progeny cells. 
Table 1: Lavaged Lung Free Cell Numbers, the Percentages of AM Among the Lavaged Cell Populations, and the Average Numbers of AM Lavaged After Air or $\mathrm{TiO}_{2}$ Exposure.

$\begin{array}{lccc}\begin{array}{l}\text { (Group) [Post- } \\ \text { Exposure Time]" }\end{array} & \begin{array}{c}\text { Total Number of Cells } \\ \text { Harvested }\left(\times 10^{-7}\right)\end{array} & \begin{array}{l}\text { \% Alveolar } \\ \text { Macrophages }\end{array} & \begin{array}{c}\text { Average Number of } \\ \text { Alveolar Macrophages }\left(X 10^{-7} \text { ) }\right.\end{array} \\ \begin{array}{l}\text { (Cont) }[1 \text { day] } \\ \left(\mathrm{TiO}_{2}\right)[1 \text { day] }\end{array} & 1.18 \pm 0.06 & \begin{array}{l}99.2 \pm 0.18 \\ 96.8 \pm 0.8\end{array} & 1.17 \\ & 1.44 \pm 0.05 & 99.0 \pm 0.1 & 1.39 \\ (\mathrm{Cont})[6 \mathrm{mths}] & 1.19 \pm 0.04 & 97.9 \pm 0.3 & 1.31 \\ \left(\mathrm{TiO}_{2}\right)[6 \mathrm{mths}] & 1.34 \pm 0.24 & & \\ (\mathrm{Cont})[1 \mathrm{yr}] & 1.55 \pm 0.10 & 99.0 \pm 0.1 & 1.53 \\ (\mathrm{TiO})[1 \mathrm{yr}] & 1.34 \pm 0.10 & 98.0 \pm 0.1 & 1.31\end{array}$

:: (Cont): control, air exposed rats; $\left(\mathrm{TiO}_{2}\right)$ : $\mathrm{TiO}_{2}$ exposed rats; [1 day]: killed one day after cessation of the 12 week exposures to air or $\mathrm{TiO}_{2} ;[6 \mathrm{mths}]$ : killed six months after cessation of exposures to air or $\mathrm{TiO}_{2} ;[1 \mathrm{yr}]$ : killed one year after cessation of exposures to air or $\mathrm{TiO}_{2}$. Unless otherwise indicated, the above data represent the means and standard error of the means of values obtained from 8 rats per group at each time point. 
Table 2: Particle Burdens in Sorted Macrophages

$\begin{array}{ccc}\text { Group } & \begin{array}{c}\text { \% Phagocytic } \\ \text { Cells }\end{array} & \begin{array}{c}\text { Ave. No. Particles/ } \\ \text { Phaoocytic Cell }\end{array} \\ \text { Low Burden } & 91.1 & 5.2 \\ \begin{array}{c}\text { Low-Medium } \\ \text { Burden }\end{array} & 98.0 & 13.8 \\ \begin{array}{c}\text { High-Medium } \\ \text { Burdan }\end{array} & 98.7 & 21.9 \\ \begin{array}{c}\text { High Burden } \\ \text { Parent }\end{array} & 98.7 & 24.1 \\ \text { Population } & 97.0 & 18.2\end{array}$




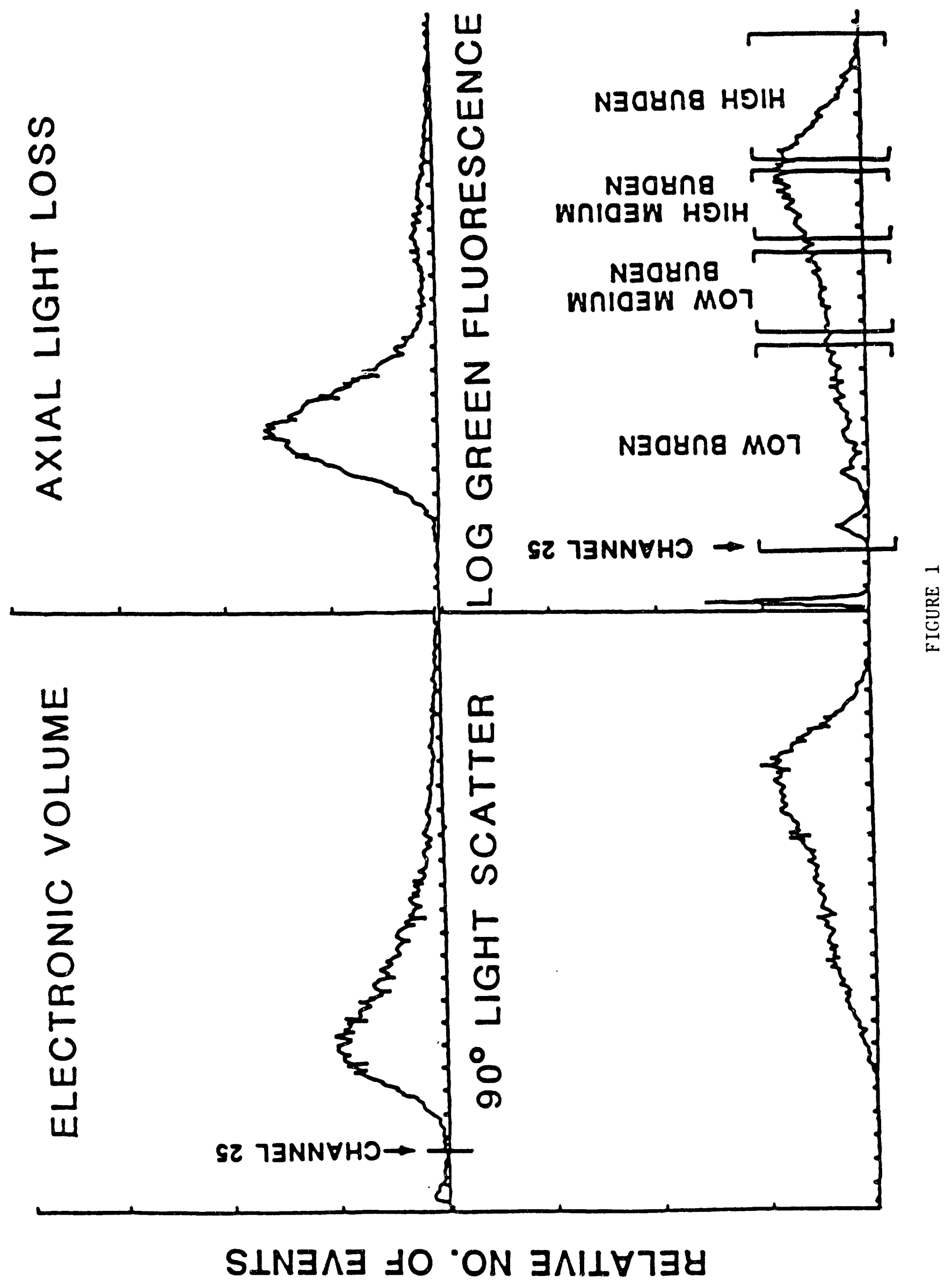



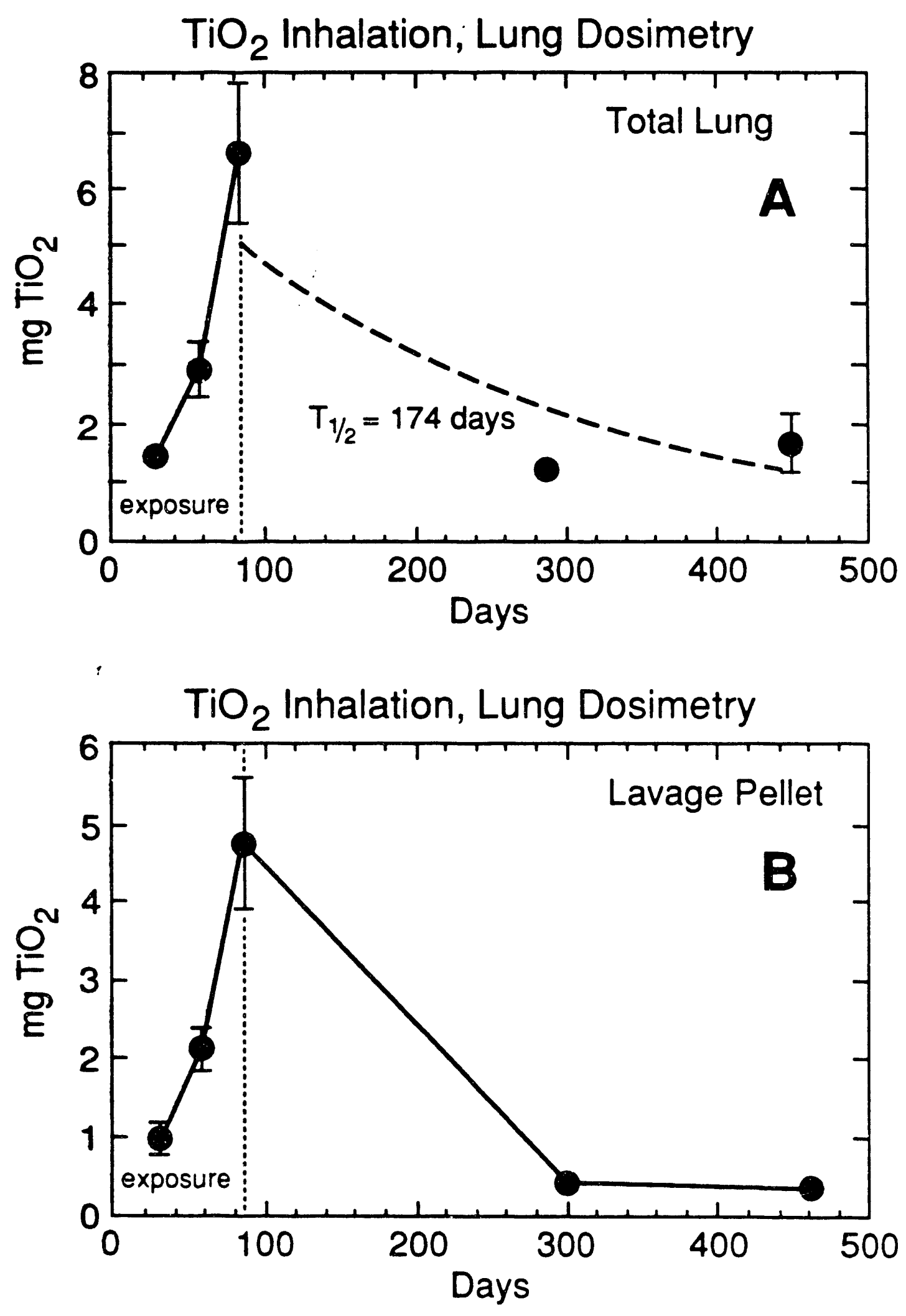

FIGURES $2 \mathrm{~A}$ and $2 \mathrm{~B}$ 


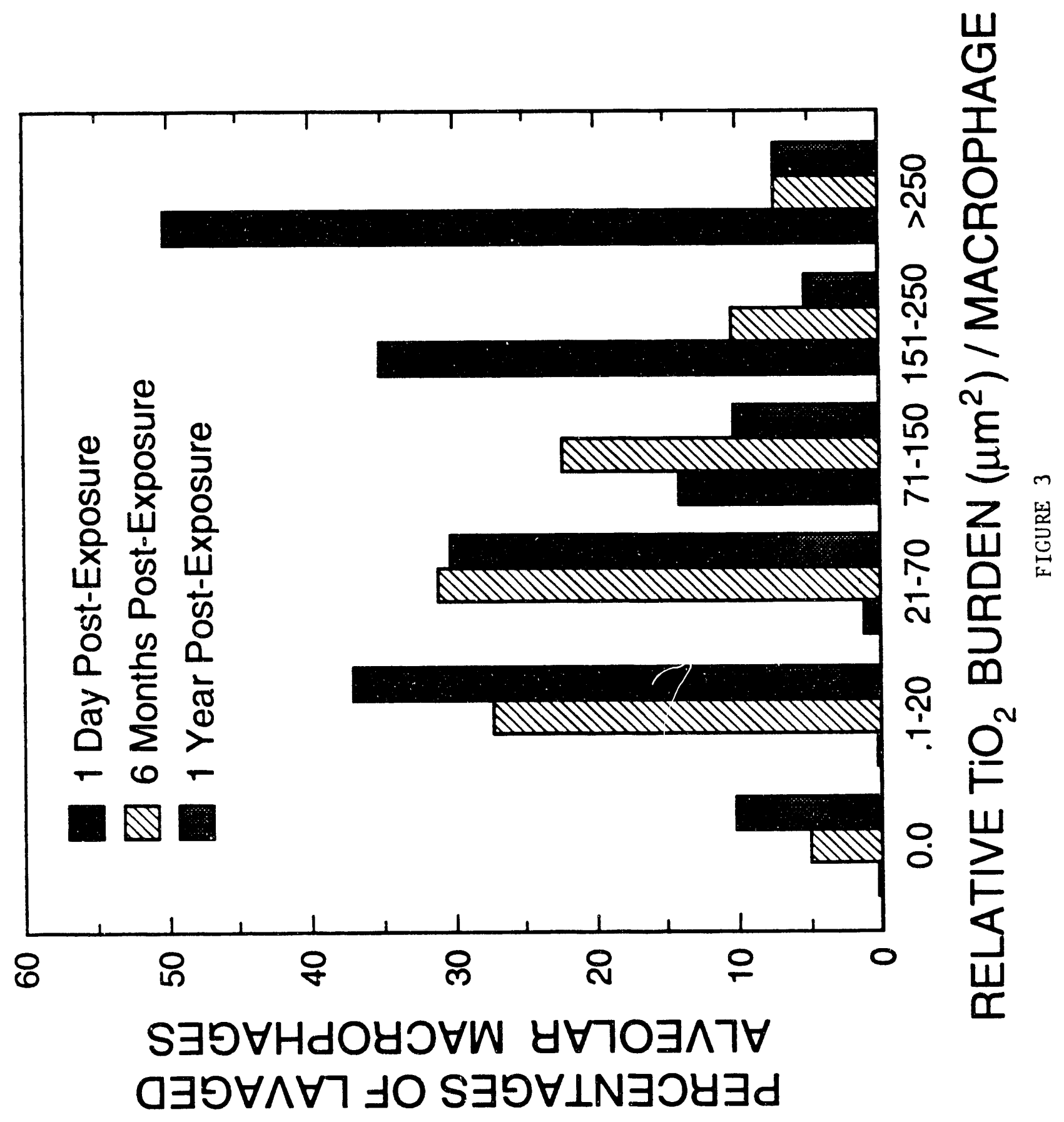




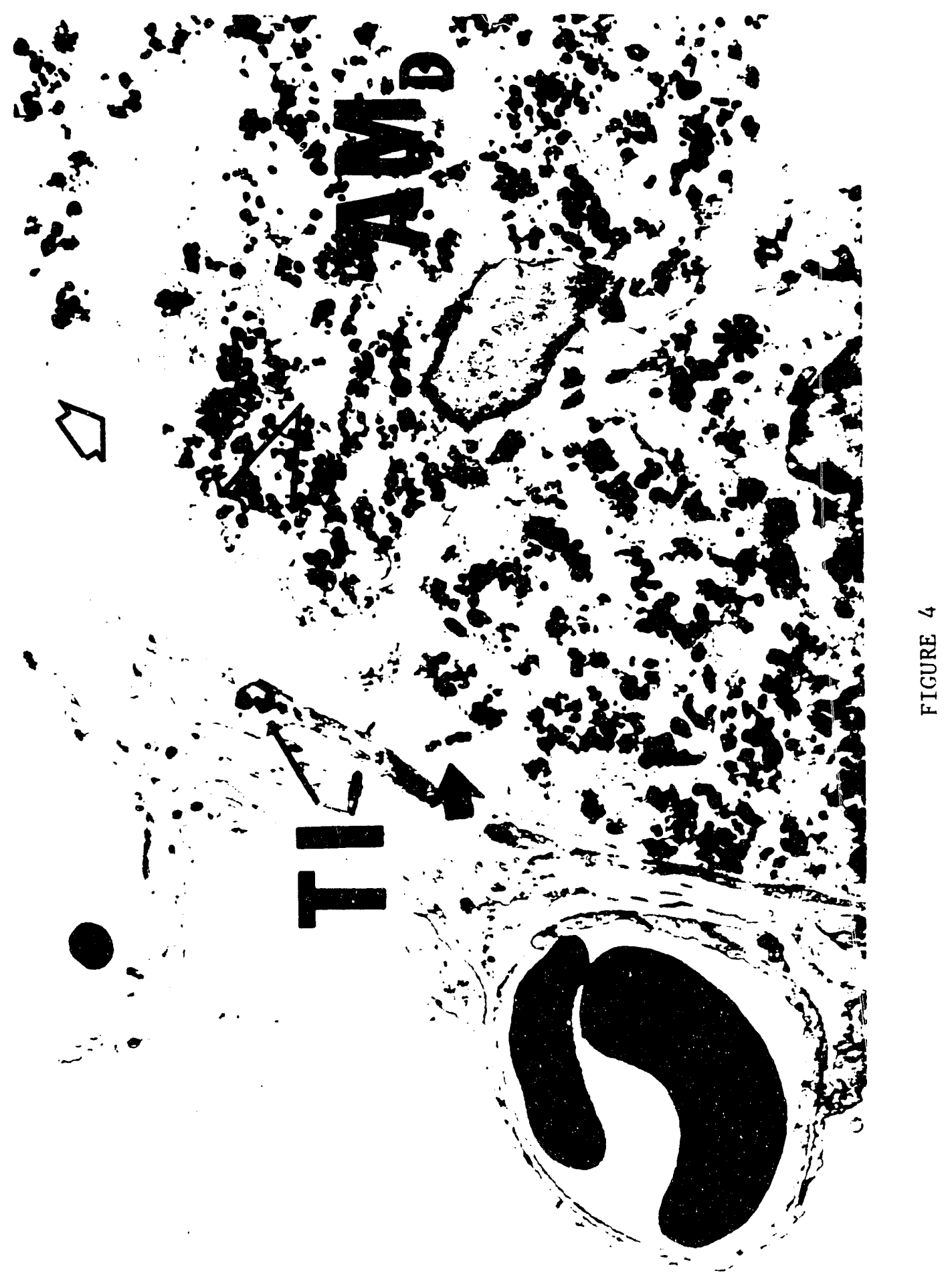




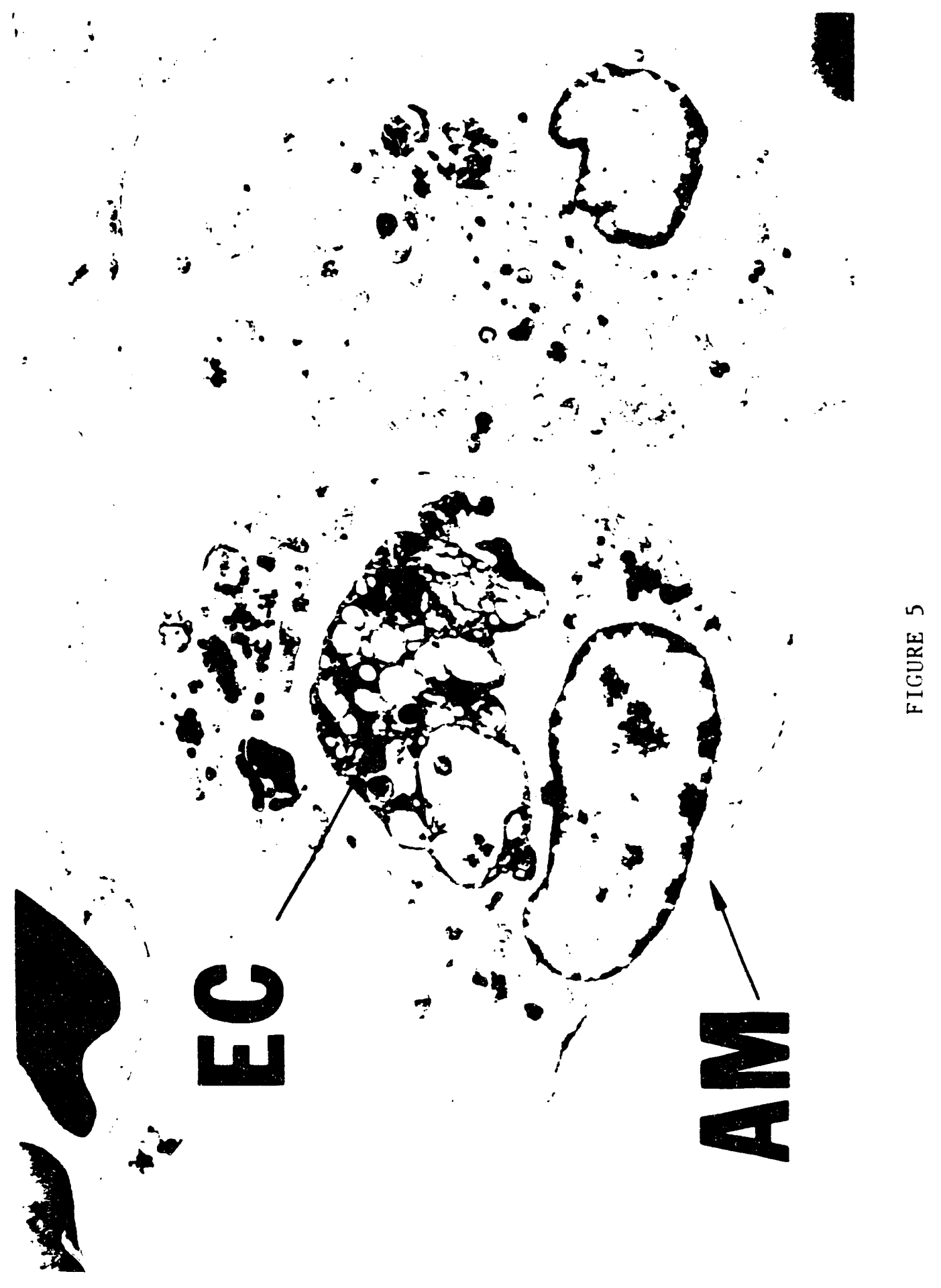




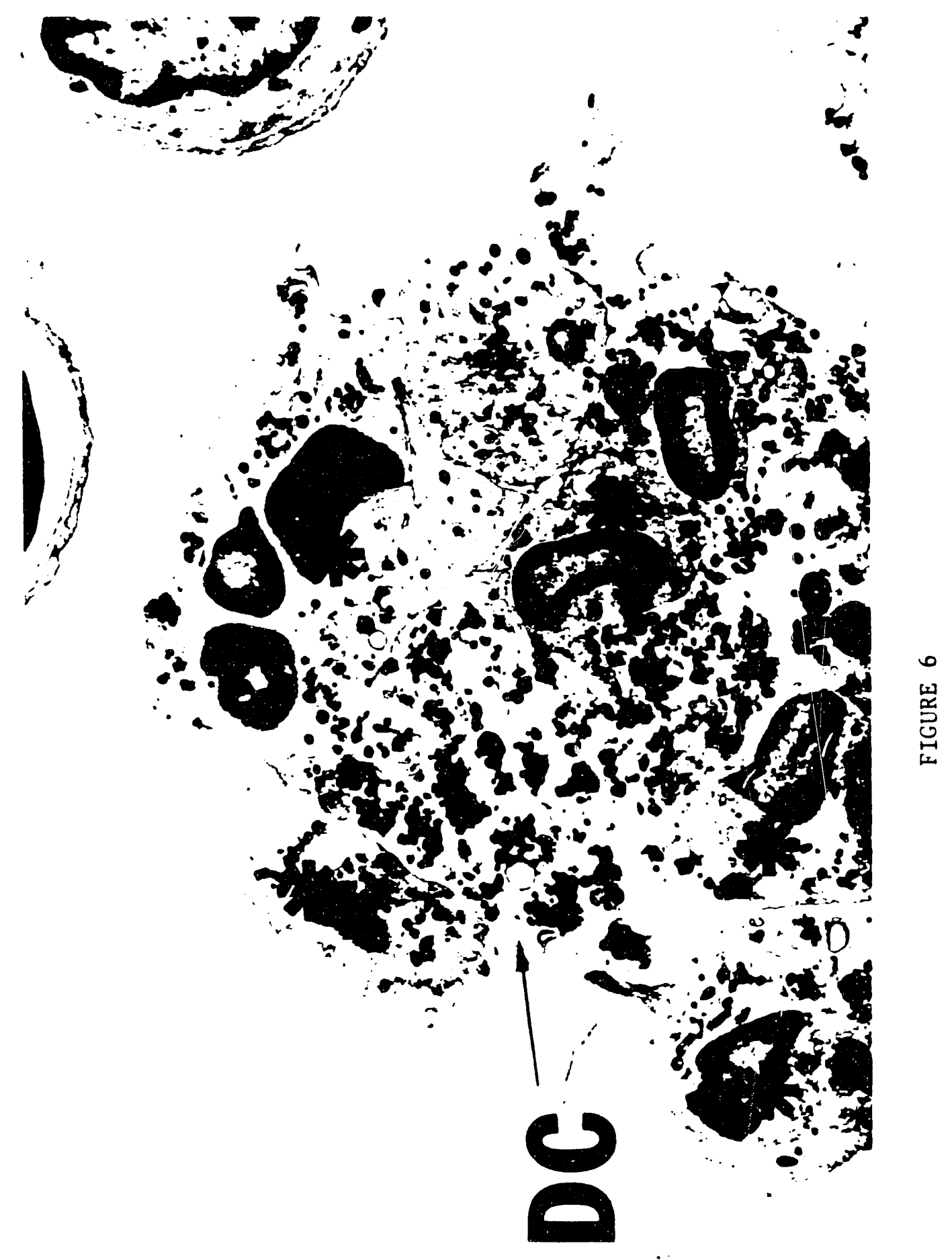




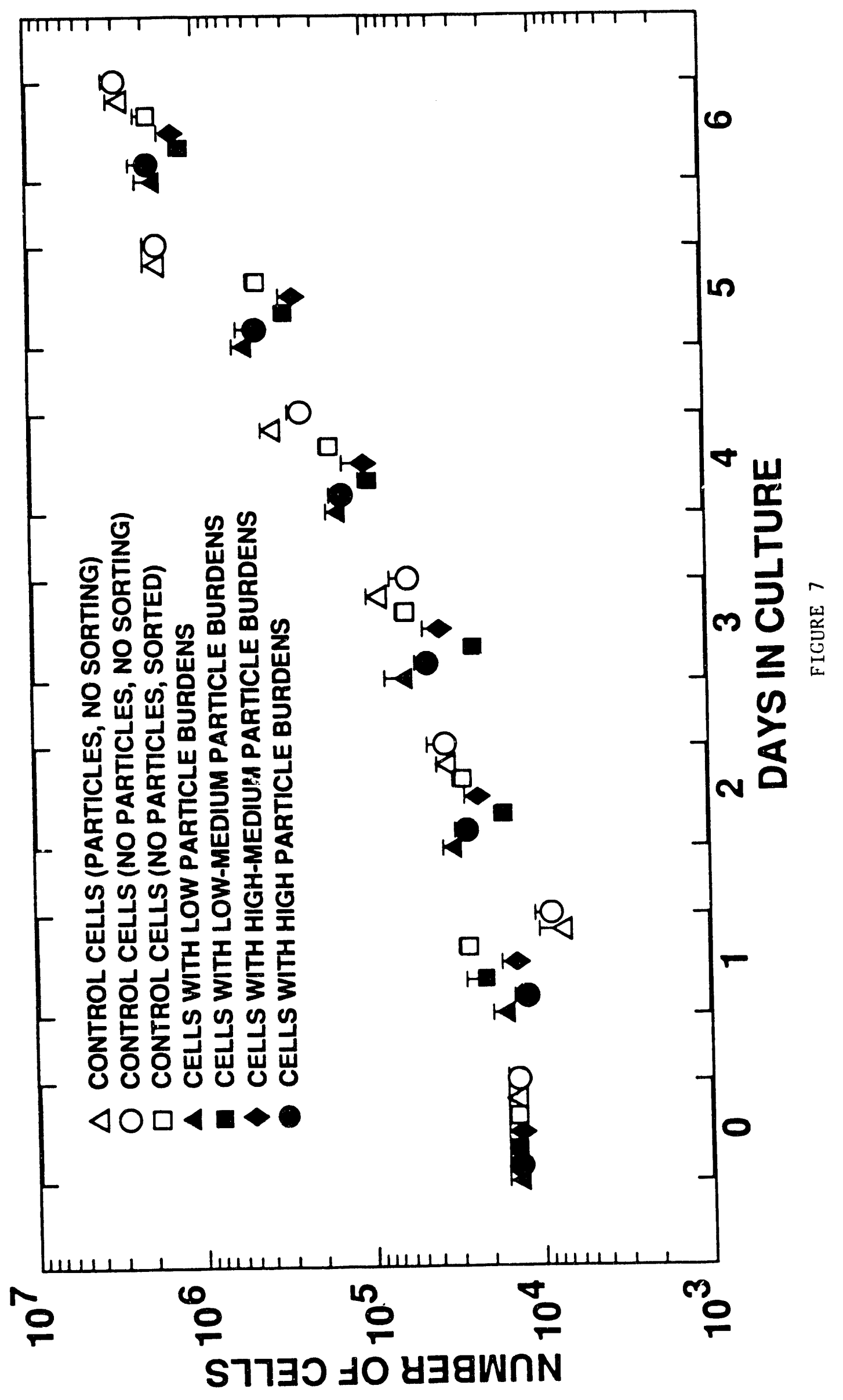



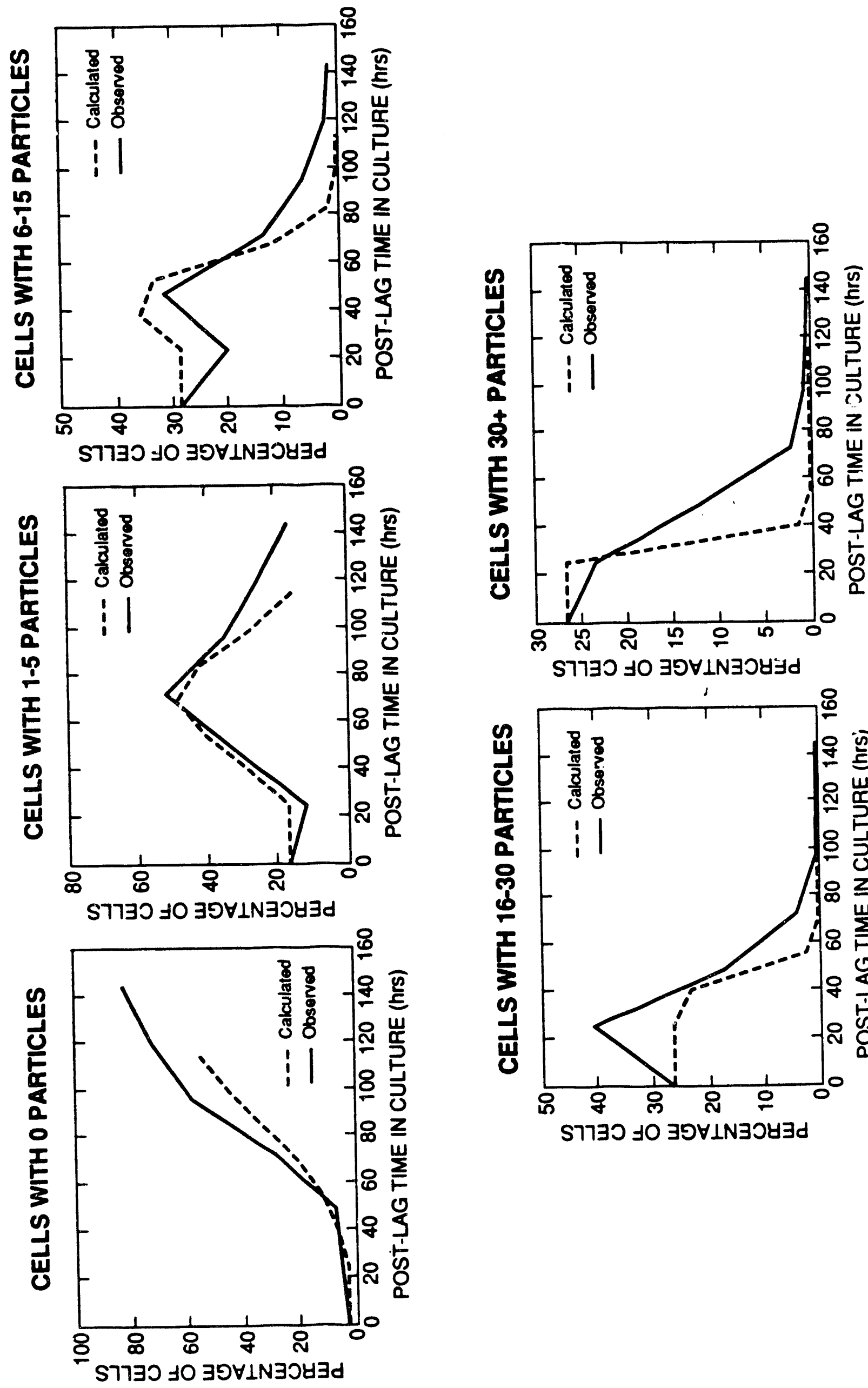

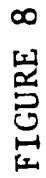

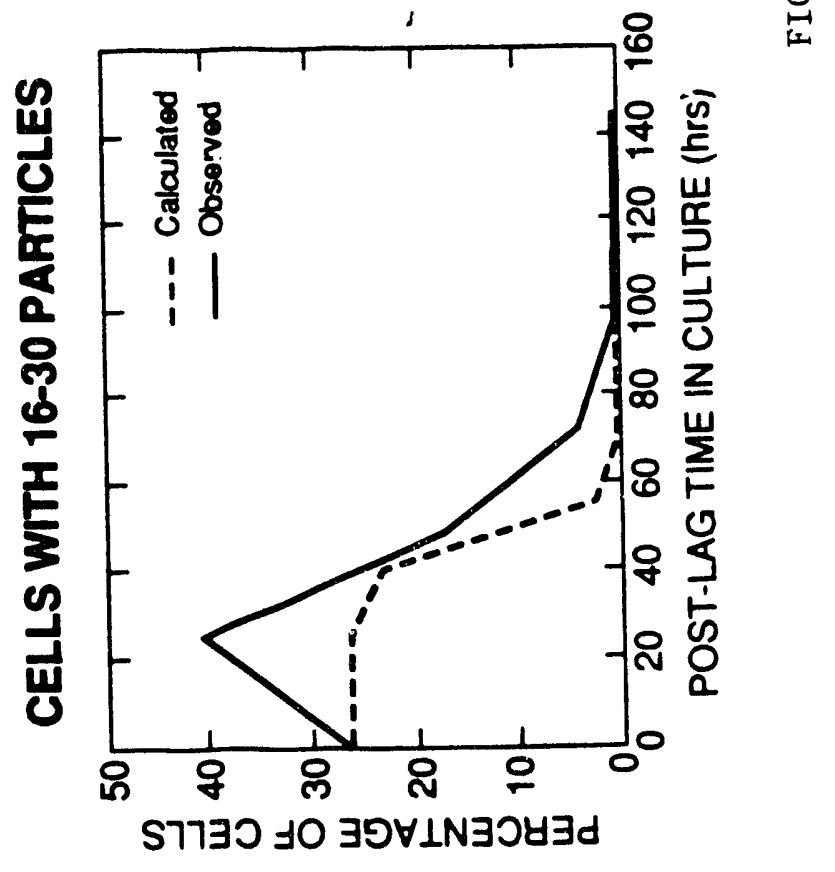



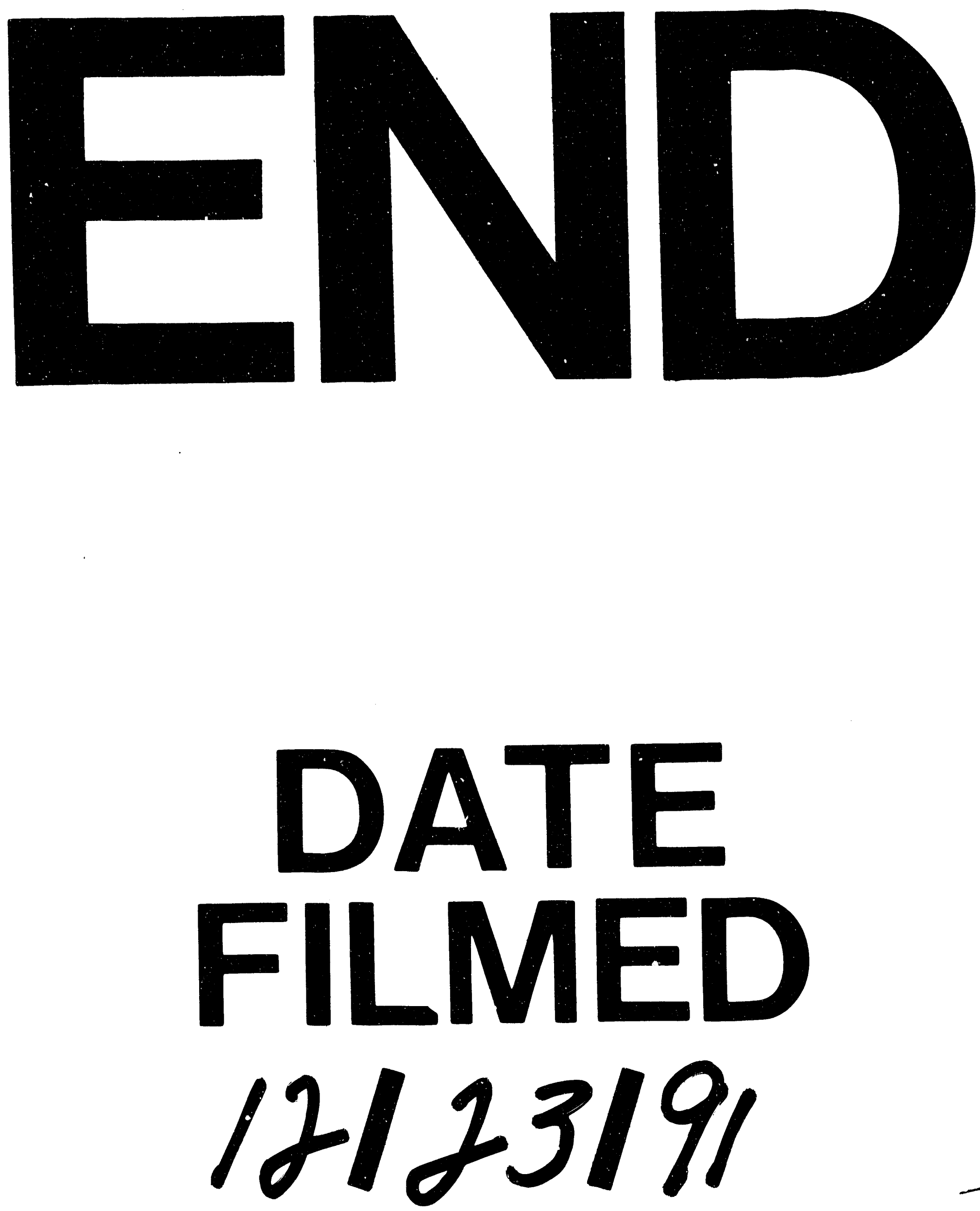


$$
\longrightarrow
$$

